\title{
Universidade empreendedora - um método de avaliação e planejamento aplicado no Brasil
}

Silvio Liberato De Moura Filho

Doutorando em Engenharia Industrial pela Universidade Federal da Bahia. Mestre em Administração pela Universidade Federal da Bahia/ UFBA

silvioliberatomoura@gmail.com

Angela Machado Rocha

Doutora em Energia e Ambiente (UFBA). Chefe do Núcleo de Propriedade Intelectual (NIT-UFBA) Professora do Instituto de Ciências da Saúde da Universidade Federal da Bahia/ UFBA anmach@gmail.com

Eduardo Oliveira Teles

Doutor em Engenharia Industrial. Trabalha com inovação e tecnologias assistivas, modelagem e desenvolvimento de ferramentas de apoio à decisão. Professor e Pesquisador no Instituto Federal da Bahia UFBA

eoteles@gmail.com

Ednildo Andrade Torres

Pós doutorado na FAMU/FSU US. Doutor em Energia pela UNICAMP. Coordenador do Laboratório de Energia e Gás (LEN), da Escola Politécnica da Universidade Federal da Bahia/ UFBA

ednildotorres@gmail.com

\section{Editor Científico: José Edson Lara}

Organização Comitê Científico

Double Blind Review pelo SEER/OJS

Recebido em 01.09.2018

Aprovado em 27.12.2018

Este trabalho foi licenciado com uma Licença Creative Commons - Atribuição - Não Comercial 3.0 Brasil 


\title{
Resumo
}

Em que pesem as políticas de apoio do Sistema Nacional de Inovação, no Brasil, a maioria das universidades não é considerada Empreendedora. A literatura apresenta trabalhos neste campo, mas identificamos lacunas no sentido de apresentar um processo metodológico para avaliar a planejar os elementos na concretização dessa jornada. O presente trabalho refere-se à concepção e aplicação de uma metodologia de avaliação e planejamento de um Ecossistema de Inovação de uma universidade. Com esse propósito, foi utilizado o estudo de caso de uma instituição privada, com cerca de oito mil alunos, localizada na região Nordeste do país. A metodologia considerou o direcionamento estratégico da instituição, o corpo estrutural interno do ecossistema e o processo de gestão da inovação. Foram gerados nove núcleos chamados de Elementos Direcionadores do ecossistema, bem como recomendações para sua efetivação. Tudo isso foi realizado como forma de materializar o funcionamento de uma Universidade Empreendedora, com impactos no desenvolvimento da região.

Palavras-chave: Universidade Empreendedora; Ecossistema de Inovação; Gestão da Inovação.

\section{Entrepreneurial university - a method of evaluation and planning applied in Brazil}

\begin{abstract}
Regarding the support policies of the National Innovation System in Brazil, most universities are not considered Entrepreneurial. The literature presentes some works in this field, but we identified gaps in the sense of presenting a methodological process to evaluate the planning of the elements in the accomplishment of that journey. The present work refers to the conception and application of a methodology of evaluation and planning of an University Innovation Ecosystem. With this purpose, a case study of a private institution was considered, with about eight thousand students, located in the northeastern region of the country. The methodology considered the strategic posicioning of the institution, the internal structural body of the ecosystem and the innovation management process. Nine cores called Ecosystem Steering Elements were generated, as well as recommendations for their effectiveness. All of this was done as a way to materialize the operation of an Entrepreneurial University, with impacts on the development of the region.
\end{abstract}

Keywords: Entrepreneurial University; Innovation Ecosystem; Innovation Management.

\section{Universidad emprendedora - un método de evaluación y planificación aplicado en Brasil}

\section{Resumen}

En que pesen las políticas de apoyo del Sistema Nacional de Innovación, en Brasil, la mayoría de las universidades no és considerada Emprendedora. La literatura presenta trabajos en este campo, pero identificamos lagunas en el sentido de presentear un proceso metodológico para evaluar a planificar los elementos en la concreción de esa jornada. El presente trabajo se refiere al diseño y aplicación de una metodología de evaluación y planificación de un Ecosistema de Innovación de una universidad. Con ese propósito, se utilizó el estudio de caso de una institución privada, con cerca de ocho mil alumnos, ubicada en la región Nordeste del país. La 
metodología consideró el direccionamiento estratégico de la institución, el cuerpo estructural interno del ecosistema y el proceso de gestión de la innovación. Se generaron nueve núcleos llamados Elementos Directores del Ecosistema, así como recomendaciones para su efectividad. Todo ello fue realizado como forma de materializar el funcionamiento de una Universidad Emprendedora, con impactos en el desarrollo de la región.

Palabras clave: Universidad Emprendedora; Ecosistema de Innovación; Gestión de la Innovación.

\section{Introdução}

O estudo da inovação envolve um conjunto de variáveis que vai desde o contexto, o ambiente, e os personagens, até os seus objetivos e conexões, sendo uma temática plural e complexa. Um processo não linear (Bramwell \& Wolfe 2008) com fronteiras que devem ser porosas, permitindo-as exercer papel relevante no contexto da transferência do conhecimento perante a comunidade regional (Lazzeretti \& Tavoletti 2005).

A posição do Brasil no $64^{\circ}$ lugar no Global Innovation índex-GII ${ }^{1}$, em 2018, por si só é uma forte sinalização que reforça a necessidade de ampliarem-se as ações coordenadas para fomentar a inovação em todo país, envolvendo a iniciativa privada, o Governo, e as Universidades, dentre outros atores. A participação desse último tem merecido uma especial atenção na gradativa e necessária mudança do seu papel, nos últimos tempos. Em recente pesquisa sobre empreendedorismo e inovação no ambiente das universidades brasileiras, promovido pela Endeavor e pelo Sebrae (2017), em mais de 70 instituições de ensino superior, os resultados demonstram que muito precisa ser feito por essa causa. A constatação geral é que a grande maioria da universidade brasileira não é empreendedora. Já os trabalhos na literatura costumam apresentar fatores de sucesso, recursos, competências ou requisitos necessários para tal conquista. No entanto, observamos lacunas no sentido de apresentar aspectos metodológicos factíveis de processos voltados para a construção dessa jornada da academia, enquanto sistema plural e complexo.

Nossa curiosidade de pesquisa se lastreia, portanto, na seguinte pergunta: como é possível avaliar e planejar um Ecossistema de Inovação de Universidade, de forma a orientá-la a ser uma Universidade Empreendedora?

\footnotetext{
${ }^{1}$ GII é um estudo anual sobre a capacidade e implementação quanto à Inovação nos países. É publicado pela Universidade de Cornell, Instituto INSEAD e pela Organização Mundial da Propriedade Intelectual, em parceria com outras organizações e instituições.
} 
O objetivo deste trabalho é apresentar uma metodologia de avaliação e planejamento de um ecossistema de inovação a ser implantado em uma universidade, propiciando que ela se torne, no médio ou longo prazo, uma universidade empreendedora. A pesquisa utilizou um direcionamento metodológico de natureza quali-quantitativa, com lógica dedutiva, num horizonte de tempo transversal. Foi utilizada uma estratégia de estudo de caso de uma universidade privada, de grande porte, com mais de 50 anos de fundada, mantida por uma instituição católica, localizada na região Nordeste do Brasil, sem qualquer tradição na área de empreendedorismo e inovação.

O estudo traz contribuições no campo científico na medida em que apresenta uma metodologia sob essa nova abordagem, identificada nas lacunas da literatura, que pode ser útil em ecossistemas existentes ou a serem implantados.

\section{Referencial Teórico}

\subsection{Ecossistema regional de inovação e a universidade empreendedora}

O campo de pesquisa sobre o empreendedorismo acadêmico tem vivenciado uma evolução, no sentido de ter adquirido maior amplitude, em especial no papel de uma nova "espécie" de universidade (Siegel e Wright, 2015). Na última década, tem ocorrido uma renovação dos atores do Sistema Nacional de Inovação, que é o arcabouço, em rede, que reúne todas as instituições envolvidas com Ciência, Tecnologia e Inovação no país. É notada a presença de novos stakeholders nesse processo, como uma nova geração de pesquisadores, estudantes, novas agências federais, associações de diversas classes, como também novos gestores de mecanismos de apoio como gerentes de incubadoras e parques tecnológicos, aceleradoras, dentre outros. Essa dinâmica gera novos tipos de redes, com complexas relações que têm que ser repensadas e atualizadas.

Um ecossistema ou sistema de inovação advém do conceito de sistemas estudados, em paralelo, por Freeman, Lundval e Nelson. Freeman citado em MCTI (2015, pág. 14) traz sua clássica definição: ..."um sistema de Inovação consiste em um conjunto de elementos interconectados, que influenciam a produção, difusão e utilização de conhecimento novo e útil do ponto de vista econômico, fomentando a inovação e o desenvolvimento”. A International Association of Science Parks and Areas of Innovation (IASP), em 2018, adota a denominação de áreas de inovação, inclusive incorporou-a em seu título, em 2017, embora o conceito seja mais conhecido no Brasil como Ecossistema de Inovação (Aranha, 2016). Inicialmente, esse se 
refere a um sistema regional, mas pode ser adotado para um ambiente, habitat ou um sistema interno de uma universidade, como no caso em questão. Recentemente, O Novo Marco Legal da Inovação ${ }^{2}$ brasileiro traz essa definição como "ambientes promotores de inovação" que, resumidamente, são espaços que estimulam a inovação, peculiares à economia do conhecimento, e promovem articulações entre Governo, Instituições de Ciência e Tecnologia (ICTs), Empresas e Organizações públicas e privadas. Ainda segundo esse instrumento legal, estes ambientes englobam duas dimensões: os "ecossistemas", que se constituem em espaços como parques e polos científicos e tecnológicos e cidades inteligentes; e os "mecanismos de geração de empreendimentos" que são estruturas ou processos que abrigam projetos ou empresas como incubadoras, aceleradoras, etc.

Uma universidade caracteriza-se por um ambiente multifacetado, por isso a denominação, de Ecossistema é muito pertinente. Na literatura internacional, no que tange às universidades, o campo de estudo tem sido tratado, na sua maioria, sob o termo "Universidade Empreendedora" (Etzkowitz et al, 2000; Etzkowitz, 2003; Etzkowitz \& Klofsten, 2005; Etzkowitz \& Viale, 2010; Rothaermel et al, 2007; Zahra \& Wright, 2011; O’Shea, Chugh, \& Allen, 2008.; Siegel \& Wright, 2015). Etzkowitz \& Zhou (2008) são mais enfáticos quando afirmam que a contribuição da universidade para a inovação, em termos de desenvolvimento econômico e social, é o coração do conceito de Universidade Empreendedora.

Kirby (2006) apresenta algumas características das universidades, mostrando porque não são, em sua essência, instituições empreendedoras: “... a natureza impessoal das relações, estrutura hierárquica e muitos níveis de aprovação, necessidade de controle, regras e procedimentos, conservadorismo e cultura corporativista, ausência de talento empreendedor, etc.".

O tema Universidade Empreendedora foi valorizado por Rothaermel et al. (2007) como a linha de estudo em que os pesquisadores apontam que os atores envolvidos vivem um dilema entre a universidade tradicional, voltada para a pesquisa básica e educação, e a universidade moderna, onde são adotados o empreendedorismo e a inovação como formas de evolução natural do sistema universitário. Siegel \& Wright (2015) trazem uma nova visão de empreendedorismo e inovação acadêmicos, colocando novas abordagens no papel da

\footnotetext{
${ }^{2}$ O chamado Marco Legal da Inovação é formado pela Lei Federal n.13.243, de 11 de janeiro de 2016, conhecida como Lei da Inovação, regulamentada pelo Decreto $N^{\circ} 9.283$ de 07 de fevereiro de 2018, que estabelece direitos, deveres e possibilidades de apoio federal às Instituições Científicas e Tecnológicas-ICTs.
} 
universidade, conforme Tabela 1. O importante é termos em mente que se trata de um novo paradigma, em que os desafios não são triviais.

\section{Tabela 1}

Perspectivas tradicionais e emergentes no Empreendedorismo Acadêmico

\begin{tabular}{llr}
\hline Theme & \multicolumn{1}{c}{ Traditional perspective } & Emerging perspective \\
\hline Why & To generate direct financial returns & $\begin{array}{c}\text { To provide a wider social and economic benefit to the university } \\
\text { ecosystem } \\
\text { Student and alumni start-ups; entrepreneurially equipped } \\
\text { students; job creation in the local region or state } \\
\text { Students; alumni; on-campus industry collaborations; surrogate } \\
\text { entrepreneurs }\end{array}$ \\
How & Academic faculty and post-docs & $\begin{array}{c}\text { Accelerators; Entrepreneurship garages; student business plan } \\
\text { competitions; collaborative networks with industry and } \\
\text { alumni; employee mobility; public-private 'incubators' }\end{array}$ \\
\hline
\end{tabular}

Nota. Fonte: Siegel \& Wright (2015)

Siegel \& Wright (2015) destacam, ainda, que o empreendedorismo acadêmico deve ser repensado, salientando sua importância crescente nos últimos anos e que isto tem se constituído numa temática estratégica para as universidades. Lembram, também, algumas formas em como promovê-lo como: reconfiguração do Design Organizacional das universidades, os Ecossistemas empreendedores, a Governança público-privada e o que ele chama da Geografia da Inovação, ou seja, a relação da instituição e seus atores com o entorno, no processo de promover o desenvolvimento. No Apêndice 1, vemos um mapeamento de diversos modelos de análise de Universidade Empreendedora.

\subsection{Gestão da inovação}

Além de discutir o conceito de Ecossistema de Inovação (seja este regional ou de uma universidade) cabe a nós tratar sobre o nascedouro da inovação. Lembrar que a mesma surge através do empreendedor, seja de uma ideia, ou projeto em uma empresa existente, portanto esse ente é peça fundamental do ecossistema (Fiates, 2014). No tradicional modelo de Shane (2003, p.11), o processo estudado depende dos atributos individuais do empreendedor, mas há uma forte influência do ambiente, tanto no nível da descoberta, quanto da potencialização das oportunidades e da execução do empreendimento. Essas duas últimas variáveis envolvem o chamado processo de Gestão da Inovação. Entendê-lo, passa a ser vital para uma visão do ecossistema. 
Bessant, Tidd, \& Pavitt, (2008) argumentam que a visão moderna sobre a inovação e sua gestão pressupõe que esse campo deva ser tratado como um processo que envolve diversas áreas, e não como um tema isolado. Tais áreas, com suas respectivas etapas e competências devem ser articuladas e estruturadas, bem como desenvolvido um conjunto de práticas e rotinas para potencializar os resultados esperados. Pesquisando, na literatura, ao longo do tempo, podemos encontrar centenas de modelos teóricos que buscam dar forma aos Sistemas de Gestão da Inovação (SGI), numa temática complexa e interdisciplinar. O trabalho de Rothwell (1994) já trazia, pioneiramente, uma grande contribuição, nesta linha, tratando de categorizar os modelos de SGI desde a década de 50, tratando-os como da primeira até a quinta geração.

Silva et al. (2013) revisitam o trabalho de Rothwell e, também, realizam um vasto mapeamento sobre o tema. Eles elegem alguns modelos representativos, contudo, sem escolher um para cada categoria. Encontramos modelos bastante referenciados como o de Cooper (1993), do tipo stage-gate, com etapas sucessivas e seleção de projetos. Outro trabalho é do próprio Cooper, em 2008, que valoriza fases do processo, da ideia até a inserção do produto no mercado. Outro destaque é a proposição de Wheelright \& Clark (1992) que traz a ideia muito difundida de um funil, propondo, nesse sentido, um processo sistemático de seleção dos projetos de Pesquisa, Desenvolvimento e Inovação (P\&D\&I).

Chesbrough traz, em 2003, o conceito de inovação aberta, que se refere “à busca de fontes externas de tecnologia e inovação para guiar o crescimento organizacional, englobando atividades como geração de spin-offs e licenciamento de patentes. Docherty (2006) revisita o conceito de inovação aberta a acrescenta inovação colaborativa, joint ventures e modelos opensource. Já a contribuição de Hansen e Birkinshaw (2007) envolve muito mais que apenas o processo de MVP (Minimun Viable Product, que consiste na condição mínima para colocar o produto no mercado), trazendo disseminação da inovação dentro da Organização, e é chamado pelos autores de Cadeia de Valor da Inovação.

Goffin e Mitchel (2010) trazem um modelo com mais elementos, acrescentando, além das etapas de desenvolvimento de produto, pessoas e organização, o alinhamento com a estratégia da Organização. Por fim, um grupo de pesquisadores, como Jonash e Sommerlate (2001), trabalham com uma proposta que busca incorporar outros elementos organizacionais ao processo, envolvendo aspectos do ambiente como liderança, cultura, recursos, aprendizado, etc. Trata-se de uma proposta mais ampla, em que a inovação permeia toda a Empresa, não se limitando ao processo de P\&D. 
Na Figura 1, temos um exemplo de uma adaptação da proposta de Jonash e Sommerlate (2001) e Docherty (2006), em que o processo se retroalimenta, proporcionando uma espécie de capacitação dinâmica e evolutiva, gerando melhorias contínuas ao mesmo, alinhada com a visão de Schumpeter (1934) sobre a inovação, no sentido de permanente criação.

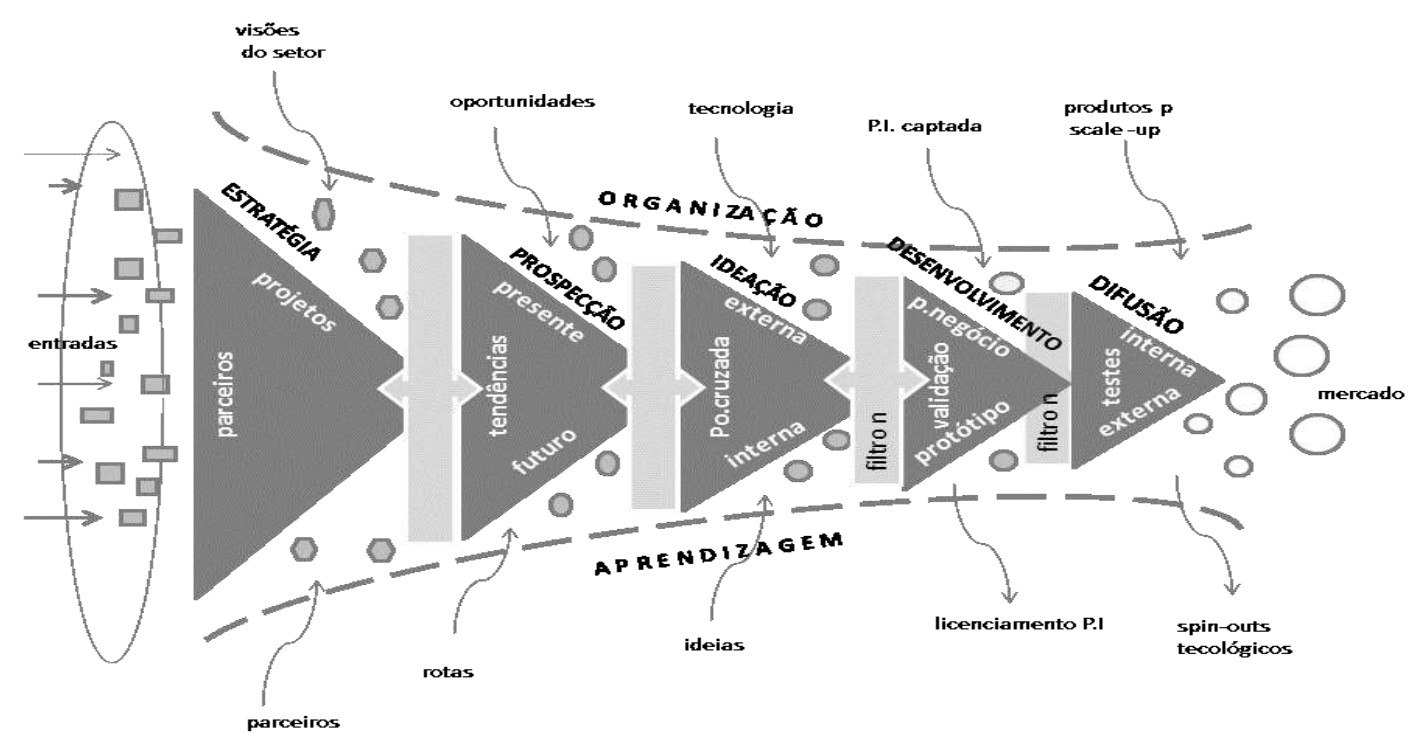

Figura 1. Modelo de processo de Gestão da Inovação Fonte: adaptado de Jonash e Sommerlate (2001) e Docherty (2006)

Como vimos, além de se entender a lógica do processo empreendedor, com o nascimento da inovação e seu processo de gestão, uma universidade tem a tarefa complexa de propiciar um ambiente promotor da inovação. Este ambiente precisa ser organizado e sistematizado para oferecer suporte e serviços ao empreendedor inovador, e sua realidade interna vivencia um conjunto de relações em redes. Essas redes internas do Ecossistema de Inovação da Universidade por sua vez, também se inter-relacionam com o ambiente regional, num processo conhecido como hibridização cruzada. A seguir, vamos apresentar os procedimentos metodológicos do estudo.

\section{Metodologia}

A partir da pesquisa do referencial teórico e da escolha dos estudos com melhor aderência ao nosso caso, a construção da metodologia seguiu 4 etapas, de acordo com a Figura 2: 


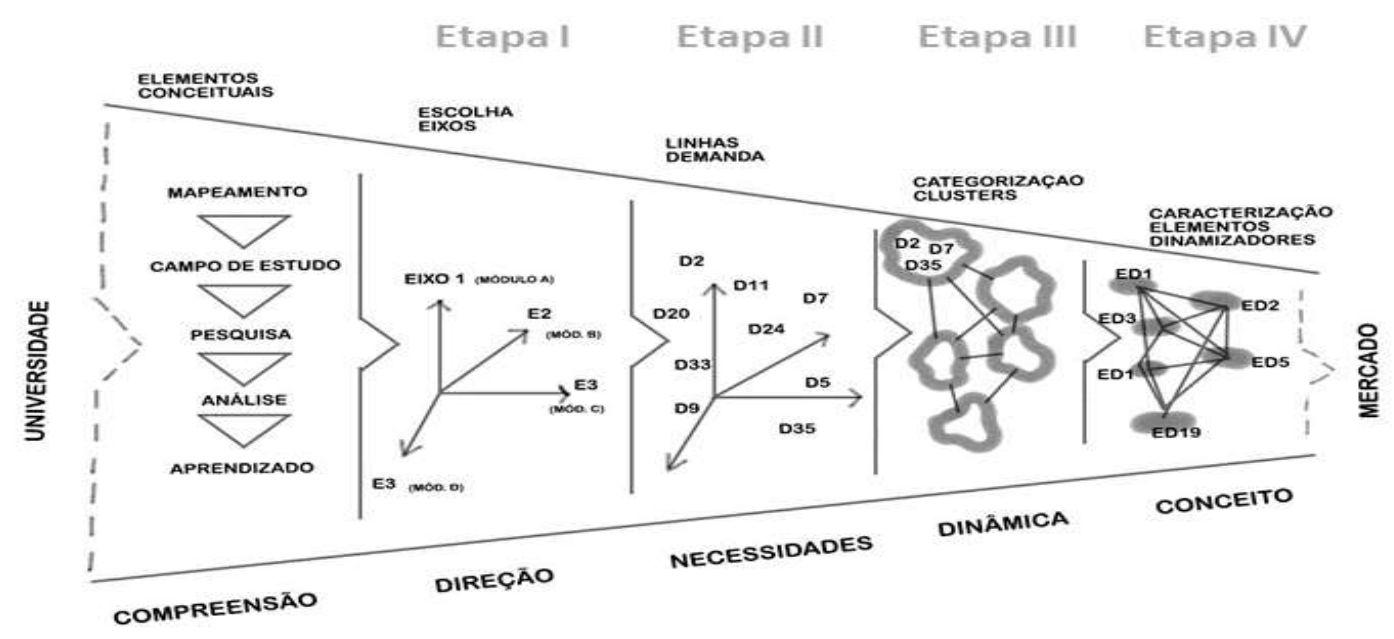

Figura 2. Modelo metodológico de avaliação e planejamento de Ecossistema de Inovação de universidade

\subsection{Etapa I: Escolha dos eixos para construção do modelo metodológico}

\subsubsection{Eixo da estratégia}

Por uma questão de posicionamento, seja numa empresa ou numa instituição sem fins lucrativos, a inovação deve obediência a uma estratégia clara, direcionadora. Este Eixo considerou o signo estratégico para definir a linha conceitual do ecossistema em questão. Para a construção do mesmo, foram utilizadas as diretrizes definidas pela alta direção da instituição, ou seja, a Reitoria, material documental como o Plano de Desenvolvimento Institucional (PDI), e entrevistas com a empresa de consultoria envolvidas no reposicionamento da universidade, em maio de 2017. Ademais, outras premissas foram consideradas como: a) o contexto atual da universidade, no nível nacional e regional; b) o perfil desejado do aluno egresso; c) o tipo de empreendedorismo e inovação que se pretende (tecnológico, de alto impacto, social, etc.); d) a escolha de algum signo específico do ponto de vista estratégico, como por exemplo, foi escolhida pela Reitoria, dentre os Objetivos de Desenvolvimento Sustentáveis (ODS) da Organização das Nações Unidas (ONU), a questão da sustentabilidade ambiental.

\subsubsection{Eixo da modelagem}

Em função do direcionamento estratégico e da expectativa de fluxo interno de serviços que serão oferecidos aos empreendedores, esse eixo constituiu-se numa plataforma desses 
processos. Ele se refere a todas as dimensões e variáveis intramuros da instituição, incluindo a estrutura física, bem como a relação da instituição com o ambiente externo. É, talvez, a parte mais complexa, pois envolve diferentes stakeholders, provedores, estrutura organizacional, clientes, redes de relações, etc. Para esta definição, utilizou-se a construção de um modelo à luz do estudo da literatura.

\subsubsection{Eixo dos serviços}

Na medida em que se inicia o processo empreendedor e a Gestão da Inovação que está inserida no mesmo, é importante que o ecossistema considere que existem diversas ações sistêmicas, com fluxo sistematizado de recursos (conhecimento, capital, insumos, etc.) que se convertem em serviços especializados para os empreendimentos apoiados. Da mesma forma que o eixo anterior, adotou-se um modelo de processo de gestão da inovação, adequado à realidade e o momento da instituição. Foi elaborado um questionário considerando as etapas do modelo e disponibilizado para os empreendedores do ecossistema, que são seus efetivos clientes.

\subsection{Etapa II: identificação do estágio atual e das demandas}

Nesta etapa, as informações dos eixos são coletadas e cruzadas. Parte das informações atende à estratégia geral do ecossistema, parte atende a avaliar o estado atual da universidade do ponto de vista do empreendedorismo e inovação, e uma terceira parte é dedicada a entender as demandas dos serviços a serem ofertados. Com estas demandas mapeadas (considerando estruturas, serviços e cultura, etc.), pôde-se projetar o que deve ser feito para atingir o nível de Universidade Empreendedora desejado.

\subsection{Etapa III: geração dos elementos dinamizadores}

Considerando os eixos escolhidos, o mapeamento do estado atual e as demandas identificadas, estas foram agrupadas e criados núcleos que prestam serviços especializados aos futuros empreendedores do ecossistema. Esses foram denominados de Elementos Dinamizadores (ED), e cada um deles possui identidade própria, com objetivos e características específicas. 


\subsection{Etapa IV: Caracterização dos Elementos Dinamizadores do ecossistema}

Nesta etapa final, cada ED é apresentado com mais detalhes, considerando sua missão, e processos que são trabalhados.

\section{Apresentação dos Resultados}

\subsection{Escolha dos Eixos}

\subsubsection{Eixo 1: estratégia}

Trata-se da Universidade Católica do Salvador (UCSal), uma universidade privada, criada em 1961, com os números apresentados na Tabela 2, sem tradição na área de empreendedorismo e inovação. A instituição pretende utilizar-se deste projeto para fortalecer seu reposicionamento como uma instituição moderna e atualizada, aberta ao novo, chegando, a partir de 2017, da marca "Nova UCSal".

\section{Tabela 2}

Principais números da universidade

\begin{tabular}{|r|r|}
\hline Alunos total & 7.647 \\
\hline Alunos Engenharia & 1.168 \\
\hline Alunos Saúde & 1.746 \\
\hline Cursos graduação & 33 \\
\hline Cursos pós-graduação & 38 \\
\hline Professores & 486 \\
\hline Pesquisadores & 60 \\
\hline Grupos de pesquisa & 54 \\
\hline
\end{tabular}

Nota. Dados fornecidos pela Pró-Reitoria de Pesquisa e Pós-Graduação em jun/2018.

De acordo com as orientações do item 3.1, incluindo dois workshops com a Comissão de Acompanhamento do projeto, formada por oito professores escolhidos pela Pró-reitoria, foi assim definido o Conceito do ecossistema:

“O Ecossistema de Inovação da UCSal terá como propósito prioritário o desenvolvimento sustentável, estimulando a criação de soluções inovadoras para atender às demandas da sociedade, a partir de um ambiente de fluxo de conhecimento e estímulo à criação de startups". 


\subsubsection{Eixo 2: modelagem}

Os modelos pesquisados na literatura foram trabalhados e ampliados com a construção de um modelo próprio, com as seguintes dimensões; a) Institucional (liderança, Estratégia e Tradição; b) Organizacional (Maturidade, Qualidade e Recursos); c) Estrutural (Especializadas, Qualidade e Recursos); d) Operacional (Processos, Serviços e ações); e, e) Cultural (Discente, Docente e Redes de relações).

\subsubsection{Eixo 3: serviços}

Considerando os modelos de gestão da inovação estudados na literatura, foi construído um modelo próprio, conforme Figura 2, adaptado de Jonash e Sommerlate (2001) e Docherty (2006), com as seguintes etapas e dimensões a) Estratégia (Parceiros, Projetos e Plataforma); b) Prospecção (Presente, Tendências e Futuro); c) Ideação (Polinização cruzada interna e externa); d) Desenvolvimento (Modelagem, Prototipagem e Validação); e) Difusão (Testes, Interna e Externa); f) Aprendizagem g) Organização (Recursos) e h) Aprendizagem (Retroalimentação do sistema).

\subsection{Identificação do Estágio Atual e das Demandas geradas pelos Eixos}

A partir do Eixo Modelagem, foi construído e disponibilizado um questionário eletrônico para os membros da Comissão de Acompanhamento do Projeto, utilizando o software SurveyMonkey (versão 2018), formado por 18 perguntas. Foram obtidos 8 questionários respondidos, representando $80 \%$ dos integrantes. Os dados foram tabulados através da exportação para o software Excel, versão 2016. A partir do Eixo Serviço, foi também elaborado um questionário em software Word composto por 16 perguntas e disponibilizado para os alunos de dez professores das Áreas de Ciências Sociais e Humanas, Engenharias, Arquitetura e Área de Saúde. Foram obtidos 64 questionários respondidos, totalizando um total final de 72 questionários respondidos, oriundos de todas as áreas trabalhadas . Em ambos os questionários foi priorizada a escala Lickert de 1 a 5 , excetuando-se as perguntas com dez alternativas de respostas, onde utilizou-se a escala de 1 a 10 . A seguir vamos apresentar as principais constatações coletadas. 


\subsubsection{Estágio atual identificado pelo eixo modelagem}

Dimensão Institucional: considerando aspectos de liderança e conexões, observou-se que a importância dada ao ecossistema no Plano de Desenvolvimento Institucional da Universidade obteve nota 3,38, vista como regular. No que tange às redes de contato, sejam internas quanto externas, os contatos mais incidentes referem-se à associação de estudantes, órgãos da administração estadual e Sistema S (Sistema que é formado pelos empresários para serviços para a área empresarial), foi adotada a nota $3 \mathrm{em}$ 5. Estes dados estão representados na Figura 3 em termos de demanda.

Dimensão Organizacional: com relação à Estratégia bem como à Tradição, ficou constatado que a Política de Propriedade Intelectual ainda não foi elaborada. Além disso, foi constatada que a experiência dos membros da Comissão de Acompanhamento com o tema da Inovação e Empreendedorismo é de menos de 5 anos.

Dimensão Estrutural: observou-se que a instituição não possuía nenhum mecanismo de geração de empreendimentos como pré-incubadora, incubadora, co-working, ou similar, apresentando apenas centro de pesquisa e empresa Junior, obtendo nota 1,75 em 5, nem tampouco graduou nenhuma empresa spin-off.

Dimensão Operacional: em termos de processos, identificou-se que não existiam serviços sistematizados oferecidos aos empreendedores e apenas atendimento genérico aos estudantes (nota geral dos serviços de 2,63 em 5). Ademais, como o ecossistema ainda não está institucionalizado, as ações nesta área não são consideradas para efeito de avaliação docente, bem como ainda não existe uma sistematização permanente de demandas da sociedade que esteja vinculada a projetos de inovação. Os membros da Comissão entenderam que mesmo nesse estágio, ainda assim existiam ações de sensibilização e capacitação dos empreendedores, mas ainda em pequena escala, ranqueando-os com nota 4,13 .

Dimensão Cultural: considerando a visão dos líderes da Comissão de Acompanhamento, eles ranquearam com nota geral 3,63 em 10 o perfil dos estudantes em termos de Características de Comportamento Empreendedor (CCEs). As características que mais precisam evoluir foram Estabelecimento de Metas e Propensão a Riscos bem como a Construção de Redes. Já o perfil dos professores foi melhor ranqueado, com nota 5,25 em 10. As características que mais precisam ser melhoradas foram também Planejamento, Propensão à Riscos e Construção de Redes. Para finalizar, observou-se que muito precisa ser feito em termos de divulgação e comunicação das ações sobre Inovação e Empreendedorismo (nota 2,5 em 5). 


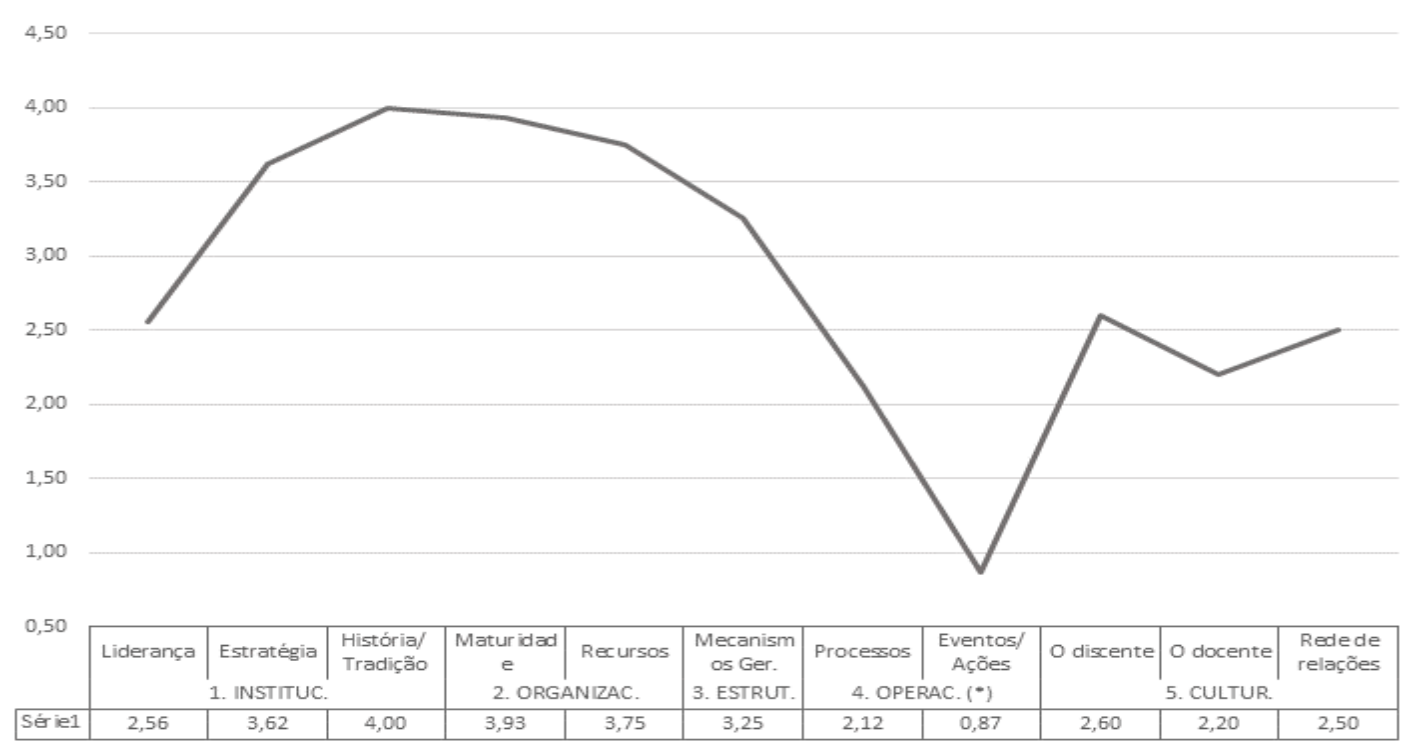

Figura 3. Demandas identificadas pelo estágio atual e Eixo Modelagem

Importante ressaltar que, na dimensão Operacional, o item Serviços não está detalhado no mapa anterior, pois será estudado a fundo no item seguinte, a partir do seu Eixo específico.

\subsubsection{Demandas Identificadas pelo Eixo Serviços}

Estas demandas foram colhidas a partir do questionário oferecido aos estudantes com relação a questões culturais que envolvem perfil do estudante e dos professores, dentre outras, bem como questões operacionais do processo de Gestão da Inovação e suas etapas relacionadas.

Com relação às ações de Promoção das atividades da Inovação e Empreendedorismo (Disseminação, Sensibilização e Capacitação), em que os professores ranquearam com nota 4,13, os estudantes foram mais conservadores e atribuíram nota 3,09 em 5, demonstrando terem visões bem distantes. Inversamente, quanto às atividades de Divulgação e Comunicação das ações sobre o tema, enquanto os professores ranquearam em 2,5, os estudantes foram mais receptivos, atribuindo nota 3,7 a este item.

Com o propósito de mensurar a demanda por cada CCE, e poder planejar possíveis serviços a serem oferecidos aos empreendedores, foi identificado o perfil dos estudantes e professores a partir da visão dos estudantes como também da visão dos líderes da Comissão de Acompanhamento. As demandas maiores para o estudante foram na área de Qualidade e Eficiência e Planejamento. Já para os professores foram identificadas as demandas relativas a Planejamento e Riscos Calculados, conforme Figura 4. 


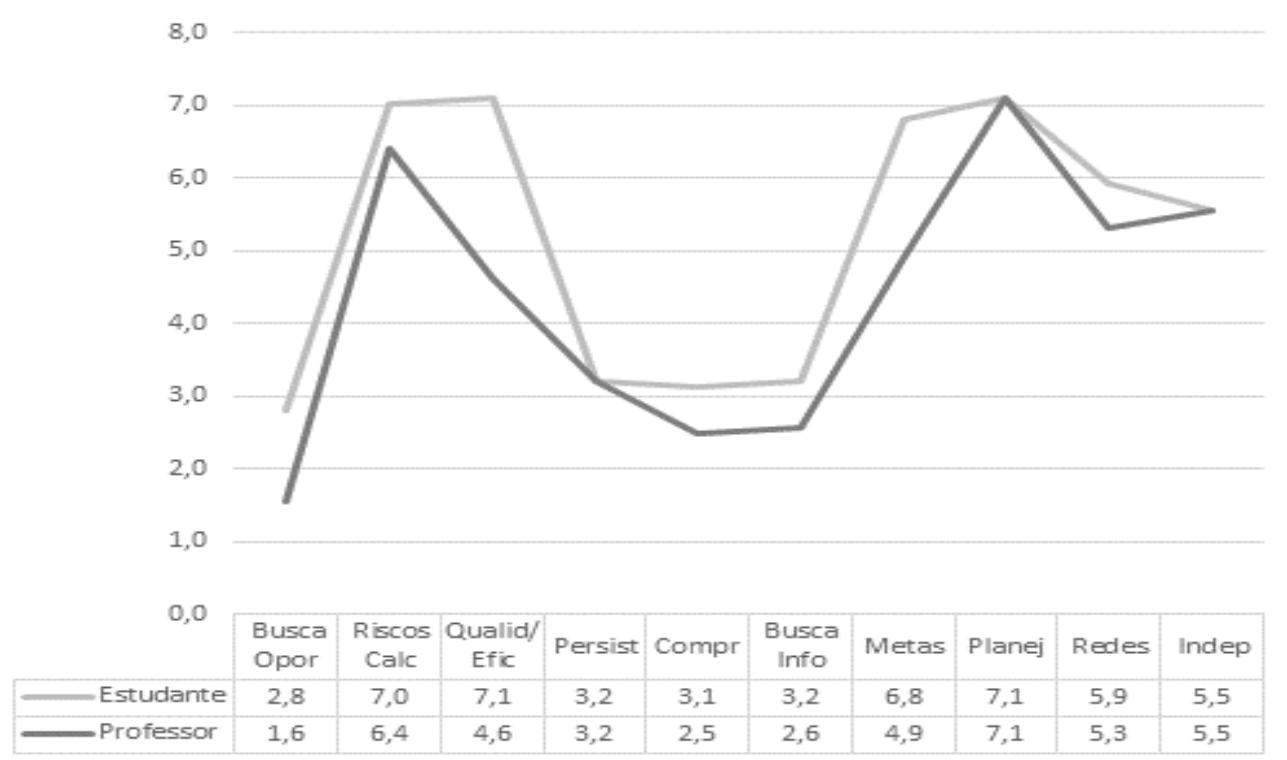

Figura 4. Mapeamento de demandas sobre perfil dos estudantes e professores

Com relação aos serviços relativos ao processo de Gestão da Inovação, vamos detalhar a seguir cada etapa do processo.

Na média geral, o grupo de serviço mais demandado foi o da etapa de Desenvolvimento, com média de 3,78 e desvio padrão de 1,13. Em termos de Desvio Padrão e Variância, os serviços de Difusão se destacaram, com valores 1,176 e 1,383, respectivamente, conforme Apêndice B. Do ponto de vista individual, o serviço que teve maior média, dentre todos foi o de Prospecção de Tecnologias Existentes, com valor de 3,98. Em relação à etapa da Estratégia, os serviços mais demandados foram sobre Mapeamento de Rotas Tecnológicas $(3,72)$ e o que foi menos demandado foi Tendências de Consumo $(3,17)$ que alcançou a menor pontuação dentre todos os serviços, conforme Figura 5. Ainda nessa Etapa de Estratégia, realizando uma avaliação cruzada, conforme Apêndice $C$, dentre os cursos pesquisados, os da área de Arquitetura lideraram, apresentando demanda mais elevada, com valor 4,50. Já em termos de demandas por semestre, embora distribuídas, os alunos do $3^{\circ}$ ao $4^{\circ}$ semestre foram os que tiveram mais demanda neste item $(5,00)$. Na etapa de Prospecção, os serviços identificados como mais necessários foram Pesquisas sobre Pesquisadores Líderes $(3,98)$. Já as menos demandadas foram as relativas a informações sobre Patentes $(3,50)$. Na etapa de Ideação, identificou-se uma demanda mais forte por Busca por Oportunidades $(3,86)$. Já a menos demandada foi a Formação de Times $(3,34)$. Na etapa de Desenvolvimento de Projeto, embora houvesse um certo equilíbrio geral, os serviços identificados como mais necessários foram os 
relativos a teste de produtos $(3,89)$ e os que manifestaram menor demanda foram os referentes a Construção de Protótipos $(3,69)$. Na última etapa mapeada que foi a de Difusão, as maiores necessidades diziam respeito a Proteção da Ideia $(3,94)$. Por outro lado, bem menos necessários, foram identificados os serviços de Venda e Distribuição $(3,31)$.

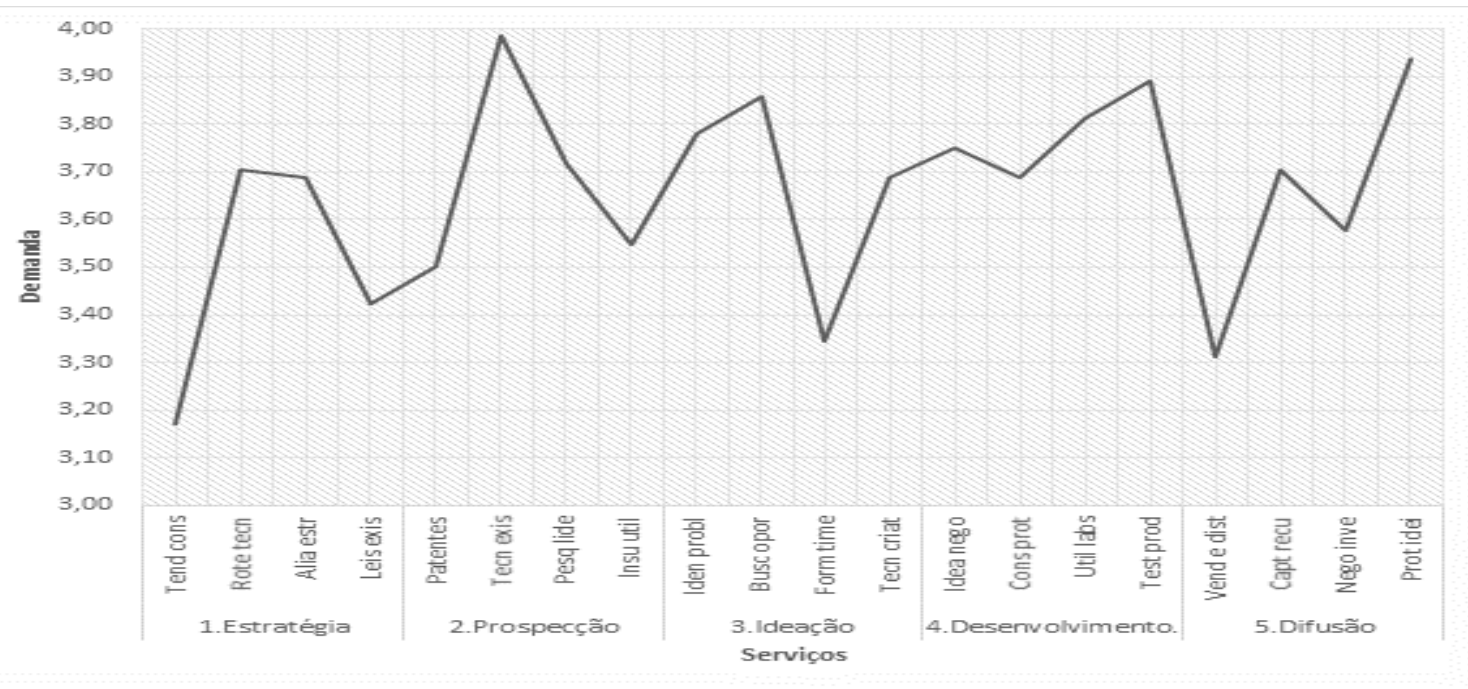

Figura 5. Mapeamento de demandas de serviços Especializados

\subsection{Geração dos elementos dinamizadores do ecossistema}

De acordo com os três eixos escolhidos (Estratégia, Modelagem e Serviços) e as demandas identificadas, estas foram reunidas e criou-se núcleos especializados para atendimento das mesmas, denominados de Elementos Dinamizadores (ED). Cada um deles possui vida própria, objetivos e características específicas, em que estarão conectados em rede. São eles que darão a dinâmica ao ecossistema e estão representados na Figura 6.

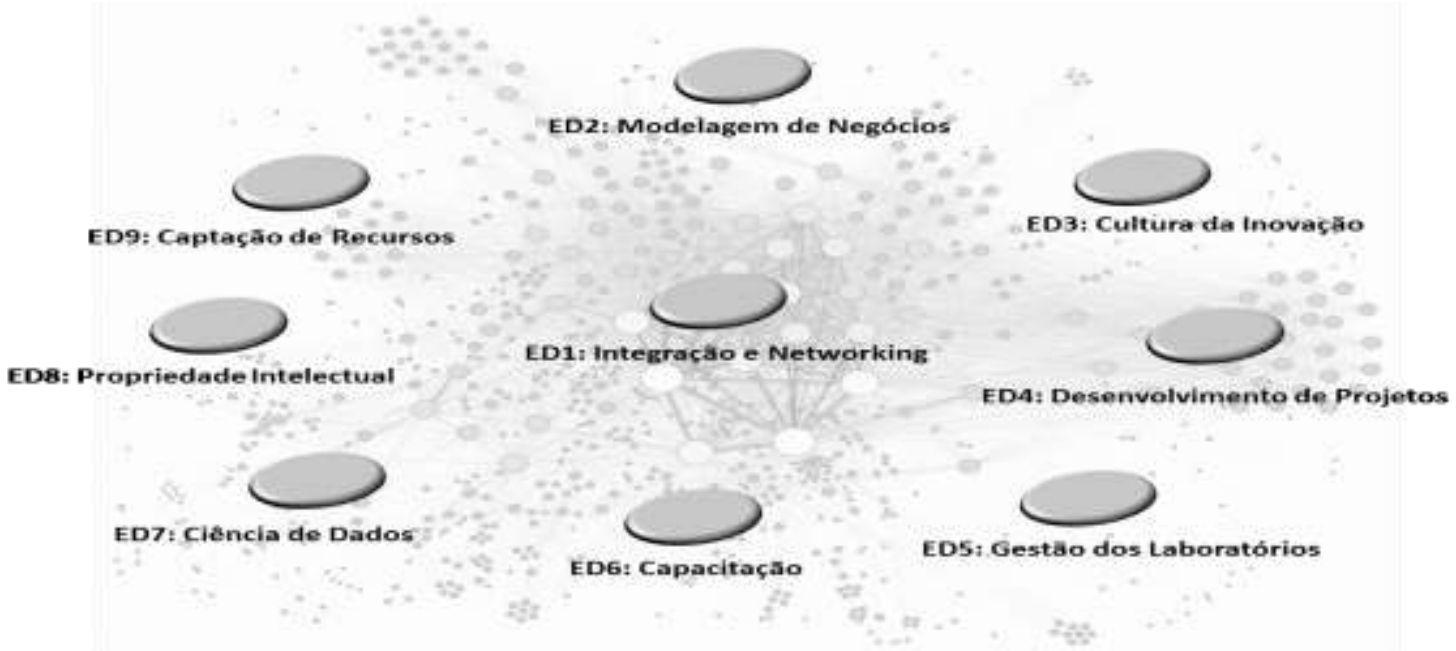

Figura 6. Ecossistema de Inovação com seus Elementos Dinamizadores 
Ao longo das fases de implantação e crescimento do ecossistema, cada elemento pode ser individualizado ou agrupado, considerando-se o estágio de maturidade do mesmo. Também em função disso, foram consideradas as dimensões de prioridade e tempo lógico para implantação de cada ED, conforme Apêndice D.

\subsection{Caracterização dos elementos dinamizadores do ecossistema}

A seguir, temos a apresentação de cada competência principal atribuída ao ED e suas características.

\subsubsection{ED1: integração e networking}

Voltado para liderar e integrar os demais elementos dinamizadores do Ecossistema de Inovação, esse espaço é o que representa e materializa o Ecossistema. Neste local, na fase inicial poderão ser alocados outros EDs, para otimizar a estrutura física. Para o sucesso do projeto, é importante que exista um local que reúna as pessoas, aconteça networking, e que sirva de referencial físico e de integração para as atividades do mesmo.

\subsubsection{ED2: modelagem de negócios}

Objetiva desenvolver modelagem de negócios através de ferramentas metodológicas rápidas e interativas, como Canvas, Design Thinking, etc. Esse equipamento será o que vai dar materialização e construção inicial às ideias dos empreendedores, com definição dos fundamentos para o sucesso dos projetos.

\subsubsection{ED3: cultura da inovação}

Seu principal objetivo é manter elevada a energia e cultura do empreendedorismo e inovação, num ciclo permanente de motivação para o ecossistema. Alguns produtos nesta área podem ser palestras, workshops, gamificação, competições de projetos, hackathons, etc.

\subsubsection{ED4: desenvolvimento de projetos}

Busca avaliar aspectos completos de desenvolvimento de "produto", considerando noções de engenharia, viabilidade técnica, econômica e comercial, em que os projetos deverão ser analisados à luz de critérios dessas diversas áreas. 


\subsubsection{ED5: gestão dos laboratórios}

Visa disponibilizar a infraestrutura de laboratórios existentes e desenvolver protótipos de uma forma interativa com o ED4, seguindo uma tendência mundial nos ambientes de inovação. Funcionando como um laboratório aberto, pode-se realizar prototipagem rápida em diversas versões dos produtos.

\subsubsection{ED6: capacitação avançada}

Objetiva capacitar e envolver profissionais que pretendem se aprofundar no tema da inovação, prioritariamente na pós-graduação, usando como cases os projetos apoiados pelo ecossistema. Ademais permite uma interação entre as áreas de pesquisa, ensino e inovação.

\subsubsection{ED7: ciência de dados}

Objetiva gerir dados de todo ecossistema e apoiar os demais núcleos, em todas as fases, dando suporte à prospecção tecnológica, inteligência de mercado, tendências tecnológicas, etc., utilizando técnicas de Data Science.

\subsubsection{ED8: propriedade intelectual}

Tem como missão desenvolver as políticas de propriedade intelectual, a nível estratégico, operacional, administrativo e negocial.

\subsubsection{ED9: captação de recursos}

Busca atuar como um escritório para elaborar e desenvolver projetos para fomento a inovação, atuando um agente de captação de recursos financeiros para os projetos e o ecossistema como um todo. Para cada ED haverá uma pequena equipe cujos pré-requisitos de perfil deverão ser direcionados para seu núcleo respectivo, bem como seu plano de alocação de horas. Como dimensionamento, foi sugerida uma equipe de quatro pessoas como líderes, com experiência com inovação, e mais quatro pessoas como suporte técnico. Um desses colaboradores será contratado do mercado e os demais serão professores identificados da instituição. Todos eles alocarão, no início, em média, um terço do seu tempo ao projeto, e essa quantidade será monitorada para eventuais ajustes. 


\section{Discussão dos Resultados}

Como vimos, a metodologia apresenta uma forma de processo que se lastreia por aspectos quali-quantitativos, utilizando dados, no espaço e no tempo, permitindo uma abordagem estrutural, mas principalmente funcional do método. São utilizadas as visões dos professores líderes da Comissão de acompanhamento do projeto, incluindo de pesquisadores do ecossistema e dos empreendedores, o que permite uma triangulação das questões. As soluções são baseadas pelo que se preconiza na literatura da inovação que é "ouvir" o cliente e “validar" a solução, com Eric Ries (2011) vem preconizando desde 2007 numa abordagem de mercado. Em outras palavras, o ecossistema é concebido sem deixar de considerar o olhar dos empreendedores, futuros clientes da solução e que vão conviver neste ambiente.

Vale destacar que o ED de Cultura da Inovação, considerando no Apêndice D como prioritário, no tempo, faz parte de uma estratégia que revisita o que defende Jonash e Sommerlate (2001), em que a inovação deve permear toda a empresa e não apenas o departamento de $\mathrm{P} \& \mathrm{D}$, ou seja, deve ser difundida por toda a universidade. Isto também está em sintonia com o que prega o Novo Marco Legal da Inovação brasileiro, quando estes ambientes de "promotores de inovação", ou seja, a inovação deve ser valorizada e disseminada. Ademais, esse Ed de Cultura da Inovação deve promover a sintonia entre a área de pesquisa (ED de Gestão de Laboratórios) como também de ensino (ED de Capacitação Avançada).

A presença do ED de Integração e Networking como também dos de Modelagem e de Desenvolvimento de projetos está alinhada com a visão de Bessant, Tidd \& Pavitt (2008) que argumentam sobre a visão moderna sobre a inovação e sua gestão, afirmando que esta deve ser gerenciada como um processo que envolve diversas áreas, e não como um tema isolado.

O formato da estrutura em rede segue uma dinâmica, que vai de encontro com a antiga universidade, caracterizada por estruturas hierarquizadas e com excesso de controles (Kirby, 2006). Esse tipo de instituição vive o dilema apontado por Rothaermel et al. (2007) encontrando-se essa entre a proposta antiga e a atual, com a flexibilidade e a valorização do empreendedorismo e da inovação.

No que tange ao seu relacionamento com o entorno, é interessante notar que o ED de Ciência de Dados, juntamente com o de propriedade Intelectual, podem estar articulados com o ED de Integração e Networking, permitindo que esta nova universidade dialogue com o mercado e o sistema regional de inovação, sendo formado por uma heterogeneidade de atores. 
Foi o que Siegel \& Wright (2015) chamaram de "Geografia de inovação", estando a academia voltada para a sua terceira missão do desenvolvimento.

\section{Considerações Finais}

O presente trabalho objetivou a apresentação de uma metodologia de avaliação e planejamento do Ecossistema de Inovação de uma universidade com mais de 50 anos de fundação, situada no Nordeste do Brasil. A metodologia foi composta em quatro etapas: escolha dos Eixos da metodologia; Identificação do estágio atual e demandas; Geração dos Elementos Dinamizadores; e Caracterização dos ED do ecossistema.

Foram mantidas reuniões com a Reitoria da universidade, utilizado material documental, além da realização de dois workshops com a Comissão de Acompanhamento do projeto, formada por professores e pesquisadores. Ademais, a metodologia previu um levantamento de campo com essa comissão bem como com estudantes empreendedores da instituição, clientes do ecossistema. Após o tratamento dos dados, a metodologia conseguiu avaliar e planejar um ecossistema formado por nove Elementos Dinamizadores, que interconectados em formato de rede, oferecerão serviços especializados aos empreendedores da universidade, com conexões com o ambiente regional de inovação, possibilitando um direcionamento para uma universidade empreendedora.

Agradecimentos: este trabalho é apoiado, financeiramente, pela Fundação de Amparo à Pesquisa do Estado da Bahia- FAPESB, Brasil.

\section{Referências}

Aranha, J. A. S. (2016). Mecanismos de geração de empreendimentos inovadores: mudança na organização e na dinâmica dos ambientes e o surgimento de novos atores. Brasília: Anprotec.

Bessant, J., \& Tidd, J. (2009). Inovação e Empreendedorismo. Porto Alegre: Bookman.

Bramwell, A., \& Wolfe, D. A. (2008). Universities and regional economic development: The entrepreneurial University of Waterloo. Research policy, 37(8), 1175-1187.

Chesborough, H. (2003). Open Innovation: The New Imperative for Creating and Profiting from Technology. Boston: Harvard Business School Press.

Clark, K. B., \& Wheelwright, S. C. (1992) Structuring the Development Funnel. In S. C. Wheelwright (Ed.), Revolutionizing Product Development: Quantum Leaps in Speed, Efficiency, and Quality (cap. 5, pp. 111-132). New York: Free Press.

Cooper, R. G. (1993). Winning at New Products: accelerating the process from idea to launch. Reading: Addison-Wesley Publishing. 
Cooper, R. G. (2008). Perspective: The Stage-Gate (R) idea - to launch process-update, what's new, and NexGen systems. Journal of Product Innovation Management, 25(3), 213-232. Recuperado de: http://dx.doi.org/10.1111/j.1540-5885.2008.00296.x

Docherty, M. (2006). Primer on “'Open Innovation'”: Principles and Practice. Visions, 30(2), 13-15.

Endeavor-SEBRAE. (2016). Empreendedorismo nas Universidades Brasileiras. Recuperado de: https://endeavor.org.br/pesquisa-universidades-empreendedorismo-2016/

Etzkowitz, H., Webster, A., Gebhardt, C., \& Terra, B. R. C. (2000). The future of the university and the university of the future: evolution of ivory tower to entrepreneurial paradigm. Research policy, 29(2), 313-330.

Etzkowitz, H. (2003). Research groups as 'quasi-firms': the invention of the entrepreneurial university. Research policy, 32(1), 109-121.

Etzkowitz, H., \& Klofsten, M. (2005). The innovating region: Toward a theory of knowledgebased regional development. $R$ and $D$ Management, 35(3), 243-255. Recuperado de: https://www.scopus.com/inward/record.uri?eid=2-s2.0-

$21944441273 \&$ doi $=10.1111 \% 2 \mathrm{Fj} .1467-$

9310.2005.00387.x\&partnerID=40\&md5=861aea95e17ce8d6625befc62098a3b9.

Etzkowitz, H., \& Dzisah, J. (2008). Rethinking development: circulation in the triple helix. Technology Analysis \& Strategic Management, 20(6), 653-666. Recuperado de: https://www.scopus.com/inward/record.uri?eid=2-s2.0-

54949138894\&doi=10.1080\%2F09537320802426309\&partnerID=40\&md5=070edafad 1 3ce075f17e9a339a31fb71.

Etzkowitz, H., \& Viale, R. (2010). Polyvalent knowledge and the entrepreneurial university: A third academic revolution? Critical Sociology, 36(4), 595-609. Recuperado de: https://www.scopus.com/inward/record.uri?eid=2-s2.0-

77954259296\&doi=10.1177\%2F0896920510365921\&partnerID=40\&md5=6054c5be 891 7 faaa38cf4e45c1935387.

Fiates, J. E. A. (2014). Influência dos ecossistemas de empreendedorismo inovador na indústria de Venture Capital: estratégias de apoio às empresas inovadoras (Tese de Doutorado). Programa de Pós-Graduação em Engenharia e Gestão do Conhecimento, Universidade Federal de Santa Catarina, Florianópolis, Santa Catarina, Brasil.

Etzkowitz, H., \& Zhou, C. (2008). Introduction to special issue Building the entrepreneurial university: a global perspective. Science and Public Policy, 35(9), 627-635.

Goffin, K., \& Mitchell, R. (2010). Innovation management: strategy and implementation using the Pentathlon framework. (2nd ed.) Basingstoke: Palgrave Macmillan.

IASP. (2018). STPS and AOIs concepts. Recuperado de: https://www.iasp.ws/Our-industry/Definitions.

Jonash, R. S., \& Sommerlatte, T. (2001). O valor da inovação: como as empresas mais avançadas atingem alto desempenho e lucratividade. Rio de Janeiro: Campus.

Kirby, D. A. (2006). Creating entrepreneurial universities in the UK: Applying entrepreneurship theory to practice. The Journal of Technology Transfer, 31(5), 599-603.

Lazzeretti, L. \& Tavoletti, E. (2005). Higher education excellence and local economic development: The case of the entrepreneurial University of Twente. European Planning Studies, 13(3), 475-493. Recuperado de: https://www.scopus.com/inward/record.uri?eid=2-s2.0$21044454729 \&$ doi $=10.1080 \% 2 \mathrm{~F} 09654310500089779 \&$ partnerID $=40 \& \mathrm{md} 5=654162 \mathrm{eb} 3$ de82c90fa6e859bfe2d4b1a. 
Ministério de Ciência, Tecnologia e Inovação - MCTI (2015). Parques \& Incubadoras para o Desenvolvimento do Brasil: Benchmarking de Sistemas Internacionais de Inovação. Brasília: Autor.

O'Shea, R. P., Chugh, H., \& Allen, T. J. (2008). Determinants and consequences of university spinoff activity: a conceptual framework. The Journal of Technology Transfer, 33(6), 653666.

Ries, E. (2011). The lean startup: How today's entrepreneurs use continuous innovation to create radically successful businesses. New York: Crown Books.

Rothaermel, F. T., Agung, S. D., \& Jiang, L. (2007). University entrepreneurship: a taxonomy of the literature. Industrial and corporate change, 16(4), 691-791.

Rothwell, R. (1994). Towards the Fifth-generation Innovation Process. International Marketing Review, 11(1), pp.7-31.

Shane, S. A. (2003). A general theory of entrepreneurship: The individual-opportunity nexus. Northampton: Edward Elgar Publishing.

Siegel, D.S., \& Wright, M. (2015). Academic Entrepreneurship: Time for a Rethink? British Journal of Management, 26(4), 582-595.

da Silva, D. O., Bagno, R. B., \& Salerno, M. S. (2014). Modelos para a gestão da inovação: revisão e análise da literatura. Production, 24(2), 477-490. Recuperado de: http://www.scielo.br/scielo.php?script=sci_arttext\&pid=S010365132014000200018\&lng=en\&nrm=iso\&tlng=pt.

Zahra, S. A., \& Wright, M. (2011). Entrepreneurship's next act. Academy of Management Perspectives, 25(4), 67-83. 
Apêndice A- Modelos de análise de Universidade Empreendedora

\begin{tabular}{|c|c|c|c|c|c|}
\hline & Autor/ Categoria & Ano & & Linha de Estudo & Dimensões \\
\hline \multirow[t]{4}{*}{1} & $\begin{array}{l}\text { Todorovick, W., } \\
\text { McNaughton,R.B., Guild,P }\end{array}$ & 2011 & Funcionalista & ENTRE-U & Mobilização em pesquisa \\
\hline & & & & & Não convencionalidade \\
\hline & & & & & Colaboração com a indústria \\
\hline & & & & & Políticas da universidade \\
\hline & & & & & \\
\hline \multirow[t]{8}{*}{2} & O'Shea & 2008 & Estruturalista & $\begin{array}{l}\text { Empreendedorismo } \\
\text { Acadêmico }\end{array}$ & Fatores ambientais \\
\hline & & & & & Caracteristicas Institucionais \\
\hline & & & & & Recursos organizacionais \\
\hline & & & & & Características individuais \\
\hline & & & & & Performance das USO \\
\hline & & & & & Desenvolvimento Econômico \\
\hline & & & & & Links ambiente interno e externo \\
\hline & & & & & Suporte do Governo \\
\hline & & & & & \\
\hline \multirow[t]{5}{*}{3} & Grass & 2008 & Recursos & $\begin{array}{l}\text { Empreendedorismo } \\
\text { Acadêmico }\end{array}$ & Estratégias e políticas em $\pi$ \\
\hline & & & & & Capital Humano \\
\hline & & & & & Estoque de Tecnologia \\
\hline & & & & & Suporte dos TTOs \\
\hline & & & & & Outros apoios \\
\hline & & & & & \\
\hline \multirow[t]{6}{*}{4} & Mustar et al & 2008 & Híbrido & $\begin{array}{l}\text { Empreendedorismo } \\
\text { Acadêmico }\end{array}$ & Estratégias e Políticas \\
\hline & & & & & Tipos de USOs \\
\hline & & & & & Tipos de TTOs \\
\hline & & & & & Times das USOs \\
\hline & & & & & Fases de crescimento de USOs \\
\hline & & & & & Aspectos Regionais \\
\hline & & & & & \\
\hline \multirow[t]{5}{*}{5} & Nelles,J. e Vorley,T. & 2010 & Hibrido & $\begin{array}{l}\text { Arquitetura } \\
\text { Empreendedora }\end{array}$ & Estruturas \\
\hline & & & & & Sistemas \\
\hline & & & & & Estratégias \\
\hline & & & & & Liderança \\
\hline & & & & & Cultura \\
\hline & & & & & \\
\hline \multirow[t]{4}{*}{7} & Rasmussen,E. e Borch,O.J. & 2010 & Competencias & $\begin{array}{l}\text { Capacidades } \\
\text { organizacionais da } \\
\text { universidade }\end{array}$ & Capacid. que abrem rota de ação \\
\hline & & & & & $\begin{array}{l}\text { Capacid. que equilibram interesses } \\
\text { comerciais e acadêmicos }\end{array}$ \\
\hline & & & & & $\begin{array}{l}\text { Capacidades que integram novos } \\
\text { recursos }\end{array}$ \\
\hline & & & & & \\
\hline
\end{tabular}

Nota. Legenda: USO: University Startups; TTO: Tecnology Transfer Office; TT:

Transferência de Tecnologia 


\section{Apêndice A- Modelos de análise de Universidade Empreendedora}

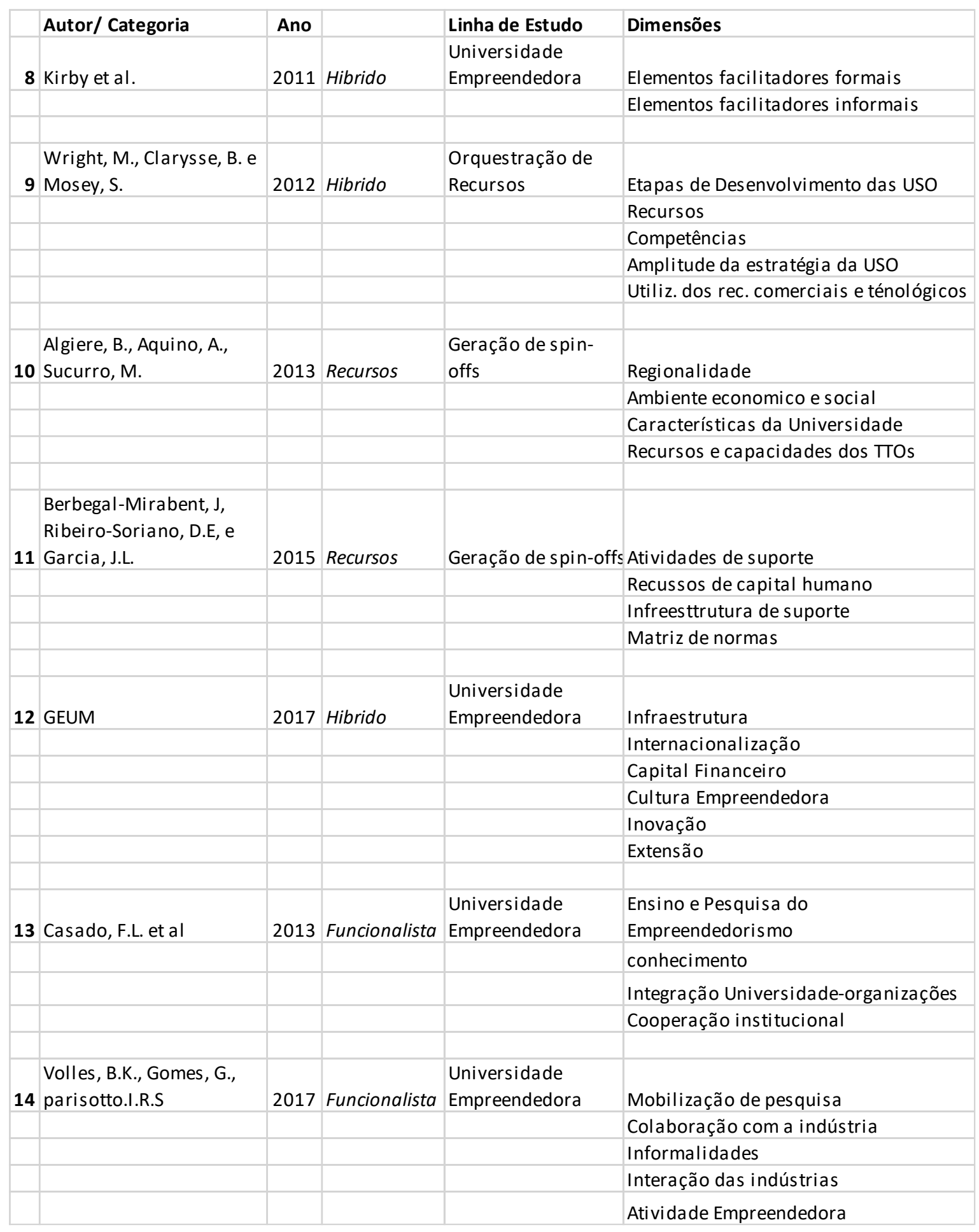

\section{Recursos}

Amplitude da estratégia da USO

Utiliz. dos rec. comerciais e ténológicos

Algiere,
2013 Recursos

offs
Regionalidade

Ambiente economico e social

Características da Universidade

Recursos e capacidades dos TTOs

de suporte 


\section{Apêndice B- Estatísticas}

\begin{tabular}{|c|c|c|c|c|c|c|c|c|c|c|c|c|c|c|c|c|c|c|c|c|c|c|c|c|c|}
\hline & $\begin{array}{l}0 \\
0 \\
0 \\
0 \\
0 \\
5 \\
0 \\
-1\end{array}$ & $\begin{array}{l}c \\
a \\
a \\
t \\
0 \\
\mathbb{1}\end{array}$ & $\begin{array}{l}\bar{z} \\
\text { di } \\
\stackrel{0}{z} \\
\bar{z}\end{array}$ & $\frac{a}{9}$ & $\begin{array}{l}\frac{a}{a} \\
\frac{g}{a} \\
\frac{a}{\pi} \\
w \\
w\end{array}$ & $\frac{9}{\pi}$ & $\begin{array}{l}\frac{a}{x} \\
\frac{c}{0} \\
0 \\
0\end{array}$ & $\begin{array}{l}\frac{0}{0} \\
\frac{1}{0} \\
0 \\
\vdots \\
0 \\
0\end{array}$ & 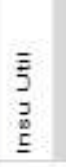 & $\begin{array}{l}\vdots \\
\vdots \\
\vdots \\
\vdots \\
\vdots \\
0 \\
\vdots \\
0 \\
0\end{array}$ & $\begin{array}{l}\bar{a} \\
0 \\
0 \\
0 \\
\frac{2}{0} \\
\underline{0}\end{array}$ & 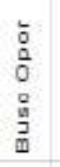 & $\begin{array}{l}\stackrel{g}{E} \\
\stackrel{E}{E} \\
0 \\
0\end{array}$ & $\begin{array}{l}\vec{a} \\
\frac{a}{2} \\
0 \\
\frac{5}{0} \\
0 \\
f\end{array}$ & $\begin{array}{l}\stackrel{0}{0} \\
0 \\
0 \\
0 \\
0 \\
\underline{0}\end{array}$ & $\begin{array}{l}0 \\
\underline{z} \\
\mathbf{z} \\
\mathbb{g} \\
\underline{0}\end{array}$ & $\begin{array}{l}\frac{a}{0} \\
\frac{a}{a} \\
\frac{\sigma}{0} \\
0 \\
0\end{array}$ & $\begin{array}{l}\frac{\mathrm{g}}{\mathrm{a}} \\
\frac{a}{5} \\
\bar{\equiv}\end{array}$ & $\begin{array}{l}0 \\
0 \\
0 \\
0 \\
0 \\
0 \\
0\end{array}$ & $\begin{array}{l}\frac{2}{0} \\
0 \\
\frac{1}{0} \\
0 \\
0 \\
0 \\
0\end{array}$ & $\begin{array}{l}\frac{\tilde{w}}{0} \\
0 \\
0 \\
0 \\
0\end{array}$ & 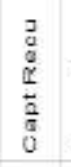 & $\begin{array}{l}0 \\
\stackrel{2}{E} \\
0 \\
0 \\
0 \\
Z\end{array}$ & $\frac{0}{0}$ & $\frac{0}{0}$ \\
\hline Hésis & 3.172 & 3,703 & 3.688 & 3,422 & 3,496 & 3,500 & 3,884 & 3719 & 3,547 & 3,688 & 3,7813 & 3,869 & 3,344 & 3,688 & 3,688 & 3,750 & 3,688 & 3.813 & 3,691 & 3,786 & 3,313 & 3703 & 3,578 & 3,998 & 3,633 \\
\hline Ermédpadr & .157 &, 144 & .149 &, 146 & .126 &, 162 &, 140 &, 147 & 166 & .134 &, 155 & .148 & .153 &, 165 &, 128 & 164 & 177 & .166 & .164 & 142 &, 177 & .166 & .174 &, 168 & 147 \\
\hline Hedizna & 3000 & 4,000 & 4000 & 4,0003 & 3,5000 & 4,000 & 4,000 & 4,000 & 4,0003 & 3,8750 & 4,000 & 4,000 & 3,000 & 4,000 & 38750 & 4000 & 4,000 & 4000 & 4,000 & 4,0000 & 3,500 & 4000 & 4,000 & 4500 & 40000 \\
\hline Hoda & 3,0 & $40^{8}$ & 4,0 & 40 & 400 & 4,0 & 50 & $40^{2}$ & 40 & 500 & 5,0 & 40 & $3,0^{2}$ & 50 & 4,50 & 50 & 50 & 5,2 & 50 & 5,00 & 50 & 5,0 & 50 & 50 & 425 \\
\hline Wodehs & 1,254 & 1,150 & 1,194 & 1,166 & 1,008 & 1,297 & 1,120 & 1,175 & 1,321 & 1076 & $1240^{\circ}$ & 1,180 & 1,224 & 1,320 & 1,022 & 1,309 & 1,413 & 1,332 & 1,311 & 1,138 & 1,413 & 1,330 & 1,389 & 1,344 & 1,176 \\
\hline Variâncoa & 1,573 & 1,323 & 1,425 & 1,350 & 1,017 & 1,683 & 1,254 & 1,380 & 1,744 & 1,157 & 1,539 & 1,393 & 1,499 & 1,742 & 1,044 & 1,714 & 1,996 & 1,774 & 1,718 & 1,291 & 1,096 & 1,768 & 1,930 & 1,806 & 1,383 \\
\hline Percertis 25 & 2000 & 3,000 & 3009 & 3,000 & 3,000 & 3,000 & 3,000 & 3,000 & 3,000 & 3,000 & 3,9003 & 3,000 & 3,000 & 3,000 & 3,000 & 3000 & 3,000 & 3000 & 3,000 & 3000 & 2,000 & 3000 & 3,000 & 3,000 & 2750 \\
\hline 50 & 3000 & 4,000 & 4000 & 4,000 & 3,500 & 4,000 & 4,000 & 4,000 & 4,000 & 3,875 & 4,000 & 4,000 & 3,000 & 4,000 & 3,875 & 4,000 & 4,000 & 4000 & 4,000 & 4,000 & 3,500 & 4000 & 4,000 & 4,500 & 4,000 \\
\hline 75 & 4000 & 5,000 & 5000 & 4,000 & 4250 & 4,750 & 5,000 & 5,000 & 5,000 & 4688 & 5,000 & 5,000 & 4,000 & 5,000 & 4,520 & 5,000 & 5,000 & 5000 & 5,000 & 4750 & 5,000 & 5000 & 5,000 & 5,000 & 4,500 \\
\hline
\end{tabular}

\section{Apêndice C- Análise cruzada entre curso, semestre x grupo de serviços}

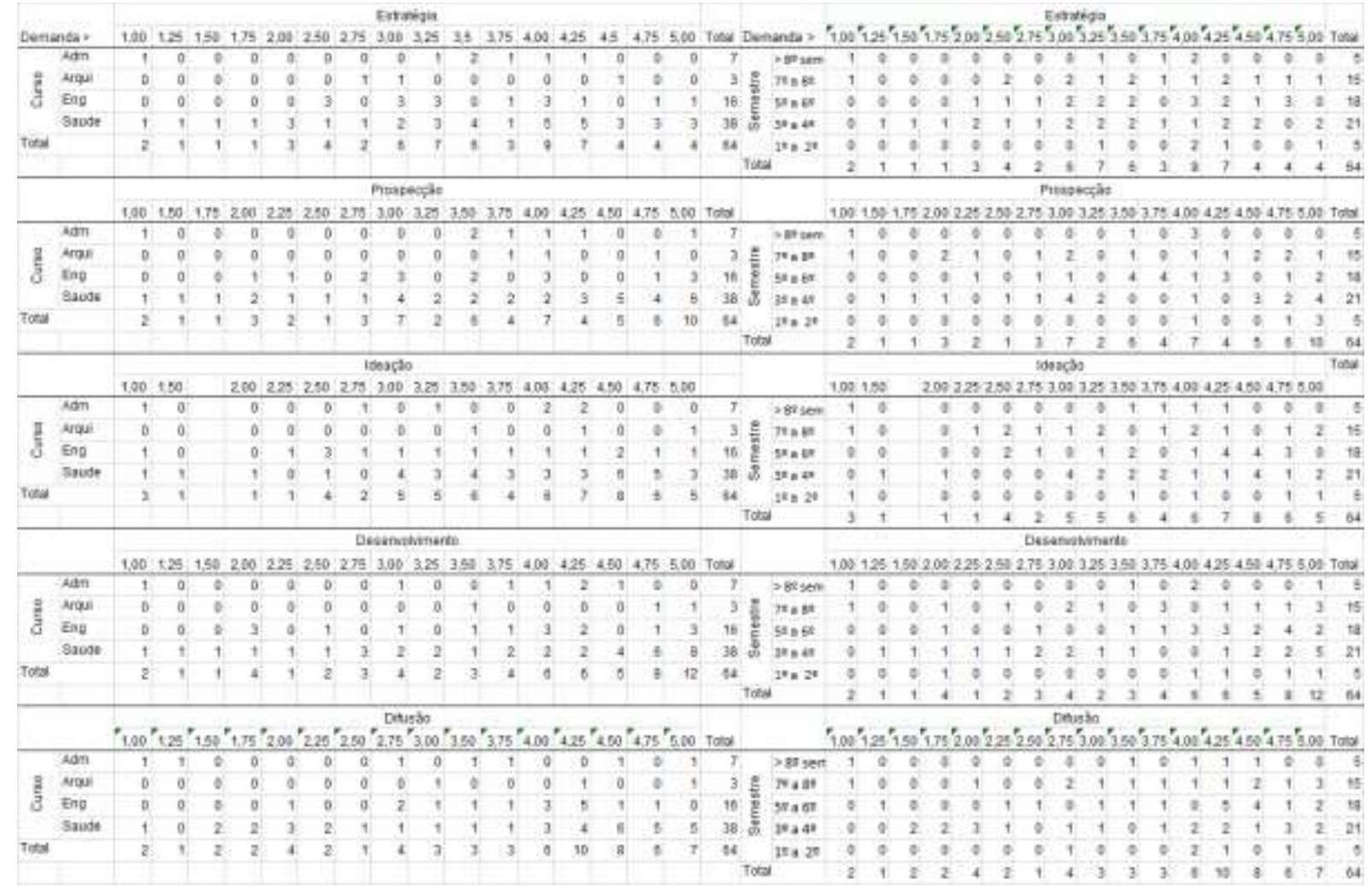




\section{Apêndice D- Distribuição dos EDs quanto à prioridade e tempo.}

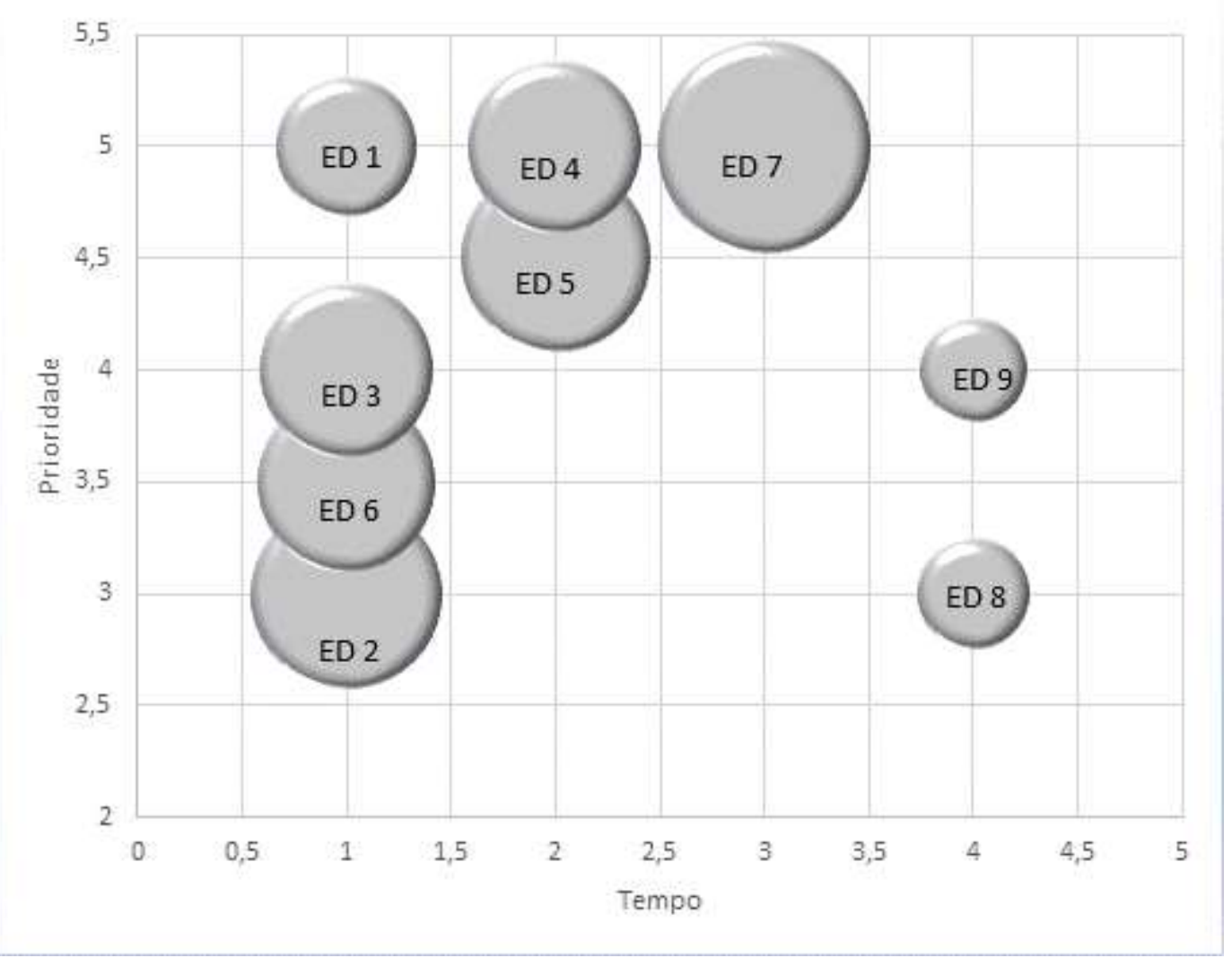

